\title{
Determinants of Emotional Language Use Preferences of Ethnolinguistic Minority Children in Antwerp, Belgium.
}

Dekeyser, Graziela; Agirdag, Orhan

\section{Corresponding author:}

Graziela DEKEYSER

Centre for Sociological Research

Faculty of Social Sciences, KU Leuven

Parkstraat 45, box 3601 - 3000 Leuven, Belgium

T: +32 163231 83/+32494889261Ｅ-Mail: Graziela.Dekeyser@kuleuven.be

Orhan AGIRDAG ${ }^{12}$

${ }^{1}$ Education and Society

Faculty of Psychology and Educational Sciences, KU Leuven

Andreas Vesaliusstraat 2 - box 3761 - 3000 Leuven, Belgium

T: +32 $16377622 \quad$ E-Mail: orhan.agirdag@kuleuven.be

${ }^{2}$ Department of Educational Sciences

Faculteit der Maatschappij- en Gedragswetenschappen, University of Amsterdam

Postbus 157801001 NG Amsterdam, The Netherlands

This is an Accepted Manuscript of an article published by Taylor \& Francis in International Journal of Bilingual Education and Bilingualism on 21/09/2018, available online: https://doi.org/10.1080/13670050.2018.1523866 


\title{
Determinants of Emotional Language Use Preferences of Ethnolinguistic Minority Children in Antwerp, Belgium.
}

\begin{abstract}
Within multilingual families, the emotionality of languages can impact individual and family wellbeing. But few studies have investigated the influence of the familial linguistic context in shaping emotional language use preferences. Guided by the Family Language Policy framework, we consider how the language use and the language attitudes of parents, siblings and children themselves affect the emotional language use preferences of children, independent of children's proficiencies in their heritage (HL) and institutional (IL) languages. We analyse unique data from over 500 primary school children (aged 10 to 12) from Moroccan, Turkish, Eastern-European and mixed descent living in Antwerp, the largest Dutch-speaking city of Belgium. We find that children's emotional preferences are strongly affected by their proficiency in the heritage language but not their proficiency in Dutch, by their parents' and siblings' language practices but not their own practice and by children's attitudes about the relative importance of $\mathrm{HL}$ and IL. Overall, the results suggest that emotional language preferences of children reflect children's own acculturation process as well as that of their families.
\end{abstract}

Keywords: children; emotional language; family language policy; language practices; language attitudes; language proficiency; 


\section{Determinants of Emotional Language Use Preferences of Ethnolinguistic Minority Children in Antwerp, Belgium.}

\section{Introduction}

During the past decades, the research on language shift and maintenance among ethnolinguistic minority groups has increased exponentially. One of the most intriguing findings in this literature is that language shift is not a general process. Depending on the context, ethnolinguistic minority members can prefer to use their heritage language (HL) or decide to shift to the institutional language (IL) (also known as majority language) (Grosjean 2010). Among adult multilinguals, in particular, the language used for emotional communication often differs from the language used in ordinary conversations (Harris, Gleason, and Aycicegi 2006; Pavlenko 2008; Chen, Kennedy, and Zhou 2012). Furthermore, ,people seem to prefer one or the other language according to the association of that language with a particular emotion culture (Dewaele 2012, 2004b, 2004a). Most of the extant research in this domain have been carried out among (young) adults and adolescents, but here we extend the literature by exploring which individual and familial characteristics influence Belgian primary school-aged children's emotional language shift.

Multilinguals differ significantly with respect to their preferred emotional language, although there is a tendency among second language learners to prefer the HL (Aycicegi and Harris 2004; Dewaele 2004b, 2004a; Ożańska-Ponikwia 2017; Perlovsky 2009; Wierzbicka 1999). We need a deeper understanding of these processes since there is reason to believe that language emotionalities affect family well-being as well as individual well-being (Chen, Kennedy, and Zhou 2012). First of all, in ethnolinguistic minority families, it is possible that children's emotional language might not be the same as those of their parent(s). This might in turn affect the emotional closeness between family members and overall family cohesion (Costigan and Dokis 2006; Pavlenko 2004). Furthermore, we know that language is a crucial 
element in individuals' emotion management development. Without language, it seems impossible to interpret emotions because there are no labels to grasp the feelings one experiences (Cervantes 2002). Understanding the connection between emotions and languages, might help to provide children better opportunities to develop those emotional languages and thus enhance their emotion management strategies.

Most studies on emotionality of languages have been restricted to studying individual linguistic characteristics (e.g. age of language acquisition and language proficiency). But individuals' linguistic development is largely determined by their social context. Especially for children, the family plays the pivotal role in the language acquisition process. For ethnolinguistic minority children, the family is the first and often also the most important social setting where they learn and use the HL. Therefore, we argue that a family perspective on emotional language shift could add crucial information on how this process unfolds. One emerging framework that focuses specifically on linguistic aspects of family life is Spolsky's (2012, 2004, 2009) family language policy. Guided by this framework, our analysis shows that children's preferences for using Dutch when they feel happy or sad are directly affected by language practices and language attitudes of various family members, independent of children's own proficiency in the HL and Dutch and socio-demographic characteristics.

\section{Literature review}

\section{Language as mirror of cultural emotion models}

Like norms, values and behavioural repertoires, basic emotion models are culturedependent. Cultures vary even in how the expression of the same emotions should be displayed. Quite a number of empirical cross-cultural studies underscore this general hypothesis. For example, children and adults with an East-Asian background are more likely than Western individuals to suppress their anger (Cole, Bruschi, and Tamang 2002; Kitayama, Mesquita, and 
Karasawa 2006; Safdar et al. 2009; Wilson et al. 2012). Likewise, Dutch children are not only more likely to act out when they are angry but also to reflect upon a situation than their Chinese peers who use more distraction strategies (Novin, Banerjee, and Rieffe 2012).

Language is not a neutral factor here because languages embody cultural meaning systems. Consider the fact that some emotional vocabulary is readily apparent in one language while absent in another. A well-known example is the Japanese term 'amae' which signifies the desire to depend upon someone else has no real equivalent in English. An English speaker might well be able to experience this emotion, but he would lack a single word label to convey this phenomenon (Niiya, Ellsworth, and Yamaguchi 2006). Wierzbicka's (2004) auto-ethnographic account about the mismatch between Polish and English terms highlights the same issue. Moreover experimental studies using language as stimuli to activate cultural patterns related to self-concept, attitudes and ethnic identity underscore the close association of language with cultural meaning systems. In other words: different languages are linked with different ways of thinking as well as feeling (BenetMartínez et al. 2002; Benet-Martinez and Haritatos 2005; Huynh, Nguyen, and BenetMartínez 2011).

Consequently, multilingual children might find themselves having to balance two 'emotional worlds'. Relatively little is known about the emotional functioning of multilingual children (Novin, Banerjee, and Rieffe 2012), but there is some indication that the emotion realm is implicated in the acculturation processes just as the more instrumental life domains are. Second-generation individuals' emotional concordance (i.e. the similarity between an immigrant's emotional pattern and the one typical of the host culture) falls neatly between those of the host culture and those of first generation migrants (De Leersnyder, Mesquita, and Kim 2011; De Leersnyder, Mesquita, and Kim 2013). However, questions remain about the role of individuals' linguistic characteristics in shaping this emotional acculturation process. 
Previous studies have suggested that emotion management is dependent upon the language abilities of children (Beck et al. 2012; Cole, Armstrong, and Pemberton 2010; Izard 2009; Pons et al. 2003). In addition, which emotional language children prefer could affect their well-being, especially when this emotional language differs from the standard of a particular social setting. For example, children who use HL as their emotional language might experience difficulties in emotion regulation in monolingual IL institutions like schools, possibly explaining previous findings on feelings of alienation and non-belonging (Agirdag, Jordens, and Van Houtte 2014) and problematic social skills (e.g. acting out) (Eisenberg, Sadovsky, and Spinrad 2005).

\section{Emotionality of Languages}

Multilinguals often differentiate their languages with regards to their emotionality. In general, first languages (L1) are more emotional than second languages (L2) that are learned later in life. For example, L2 taboo words and swear words are often perceived as funny rather than insulting (Dewaele 2017). Experimental studies also show that bilinguals recall L1 emotion words better than L2 words (Aycicegi and Harris 2004; Ferré et al. 2010). In addition, physiological indicators of emotion (e.g. heartbeat and skin reduction) increase more when bilinguals are exposed to L1 taboo words as compared to L2 words (Harris, Gleason, and Aycicegi 2006; Javier 2007). The literature posits four factors that may account for differences in emotionality of languages (Caldwell-Harris 2014). The first is age of acquisition, sometimes with explicit reference to the concept of brain maturational constraint. Since early language learning develops simultaneously with emotion regulation mechanisms in the brain, one hypothesis holds that languages acquired at a very early age have stronger connections to the amygdala (also known as the 'emotion centre' of the brain). Hence, they are more emotional than L2 languages learned later in life (Harris, Gleason, and Aycicegi 2006; Birdsong and 
Molis 2001). Strongly related to age of acquisition is the effect of relative differences in L1 and L2 proficiencies. Harris et al.(2006) found that multilinguals experience their L1 as their most emotional language only when L1 their most proficient language. A third factor, intertwined with the previous two, is the learning context of L1 and L2 languages. L1 languages are experienced as more emotional because often they were acquired in highly emotional interactive situations, e.g. between children and parents. L2 languages on the other hand, are frequently acquired in more formal learning settings such as schools (Dewaele 2010). Lastly, the emotionality of a language is determined in part by how much that language is used in everyday life (Degner, Doycheva, and Wentura 2011; Ożańska-Ponikwia 2017).

\section{Family Language Policy and emotionality of languages}

Counter to the individual level focus of most psycholinguistic studies, the FLP framework emphasizes the idea that a person's linguistic repertoire is not developed in a vacuum. The preference one particular language over another is determined by socialization experiences. Linguistic development occurs within the family context and a family's linguistic environment consists of more than language practice alone. According to the FLP framework, a family is characterized by “. . . language practices [are] - the habitual pattern of selecting among the varieties that make up its linguistic repertoire; its language beliefs or ideology - the beliefs about language and language use; and any specific efforts to modify or influence that practice by any kind of language intervention, planning or management" (Spolsky 2004, 5). Here, we restricted our analysis to practices and ideology since management strategies are often than applied more covertly (e.g. by 'medium requests' (Gafaranga 2010)) and therefore less accessible to general survey methods. 


\section{Language practice}

Parents are the main socialization agents in early years of development, and their language practices crucially impact the language use and proficiency of their children (De Houwer 2007, 2011). Regarding emotional language use, studies show that parents prefer to talk to their children, especially with regards to affective communication, in their heritage or L1 language because they feel more authentic than when conversing in their L2 (Pavlenko 2004). However, when emotional acculturation processes occur among children of migrant families, children may adopt a different emotional language than their parents, especially when they are confronted with the majority language from a young age. The proficiency of children in the IL increases with every new generation, usually at the cost of their proficiency in the HL (Alba et al. 2002; Alba and Nee 2003; Altinkamis and Agirdag 2014; Portes and Rumbaut 2001). As a result of their linguistic acculturation, children who are more proficient in the IL might then also be more likely to adopt that IL as their emotional language.

While language practices of parents and children themselves have been subject of study in language emotionality research, another crucial family subsystem has been left out of the picture. Demographic studies on language shift within the household have pointed to the crucial role of siblings (Stevens and Ishizawa 2007). While children might still use the HL with their parents, it is often found that among siblings, the IL is the dominant language. As older siblings bring the IL into the household, the exposure of their younger sibs to the IL can begin at a very early age (Kheirkhah and Cekaite 2017; Parada 2013).

\section{Language ideology}

Studies of language ideology often focus on language goals of parents such as hoping that their children grow up fluently bilingual. These goals are shaped by 'language users' evaluative perceptions and conceptions of language and language practices, based on their beliefs and assumptions about the social utility, power and value of a language in a given 
society' (Curdt-Christiansen 2016, 695). Some parents think that proficiency in the HL is crucial for establishing ethnic identity and cultural group belonging (Clycq 2009; CurdtChristiansen 2009). Yet parents also can be concerned about the socio-economic and sociocultural drawbacks of raising children with a ethnolinguistic minority language (Park and Sarkar 2007; King and Fogle 2008; Schwartz, Moin, and Leikin 2011). Though one would expect that parents' attitudes shape the languages they prefer to use with their children, FLP research has shown that this relationship is often inconsistent (Schwartz 2008; De Houwer 1999; Curdt-Christiansen 2016).

Children's ideas about the importance of learning particular languages might not necessarily be reflective of their parents' ideas. Though few FLP studies have focused on children themselves, there is some research suggesting that school-aged children are very motivated to learn the IL quickly in order to fit in with their peers (Oliver and Purdie 1998). Also, like their parents, children are well aware of the status of their HL within the broader society (Purdie et al. 2016). They might be even quicker to pick up these status differences due to the amount of time they spend in majority dominant contexts, e.g. schools. So even when children regularly use their HL, they might devalue it due to societal pressure (Agirdag 2010). Consequently, children who think their HL has lower status could be less likely to adopt HL as their emotional language.

\section{Present study}

Most psycho- and sociolinguistic studies have been carried out in English-dominant countries (e.g. U.S., Canada \& Australia), leaving European contexts relatively understudied. But many European cities have experienced significant increases in the number of ethnolinguistic minority children and their families due to successive immigration flows since WWII (Levrau et al. 2013; Timmermans, Vanderwaeren, and Crul 2003; Blommaert 2013; Crul 2015). Our study focuses on Antwerp, the largest city in Flanders, the Dutch-speaking 
northern region of Belgium. Antwerp is a highly diverse city with over 165 nationalities in 2017 and nearly $60 \%$ of new mothers report to speak a language other than Dutch with the child (Kind \& Gezin 2018). However, our understanding of the linguistic practices of children with this background and their families' linguistic environment is thin, in part because of Belgium's prohibition on collecting census data about language (Ceuleers 2008). Here we are able to consider four research questions:

RQ1: Are emotional language use preferences of children dependent upon the languages used by parents and children to communicate with each other?

RQ2: Are emotional language use preferences of children determined by their proficiency level in the HL and/or IL?

RQ3: Do language attitudes of children and/or of parents influence emotional language use preferences of children?

RQ4: What are the net effects of language practice, language proficiency, and language attitudes on the emotional language preferences of children?

\section{Data \& method}

\section{Data}

The data for this study stem from the Multilingualism in Antwerp (MINA) project (Dekeyser 2016). Initiated in September 2014, the MiNA project collected quantitative data from pupils in year 5 and year 6 of primary school (aged 10-12) in 19 Antwerp schools. Schools were selected via a disproportional quota sample, with an oversampling of low SES schools containing a high concentration of non-Dutch speakers. Our research sample is restricted to children who reported that they spoke at least one other language at home other 
than Dutch ${ }^{1}$. Due to an insufficient number of cases, 3rd generation migration children and children with no siblings were excluded from the sample. We further restricted the sample to children of Moroccan, Eastern-European, Turkish and children from mixed ethnic heritage because other ethnicities were too few to be considered separately and too diverse to be combined in to a residual category. Our analytical sample consists of 500 children. The online questionnaire was administered in Dutch during a scheduled hour at school under supervision of the first author and at least one research assistant.

All of the data of this study is based on self-reports of children. So in order for the data to be reliable, children must have been able to comprehend the questions and the phenomena to which they refer. To ensure that the survey was congruent with the children's cognitive abilities and knowledge, we implemented several strategies based on prior research and suggestions from education professionals (Bell 2016; Borgers, De Leeuw, and Hox 2000) e.g. simple wording of questions and instructions, short tasks, limited use of vague quantifiers and avoidance of negations. Since to our knowledge, there are little to no Flemish surveys specifically tailored to both the topic of the paper and the age and socio-cultural background of the children in our sample, we took multiple efforts to enhance the validity of our own survey e.g. a preliminary version of the survey was adjusted after a review by an external

\footnotetext{
${ }^{1}$ This was a general question to differentiate between children from monolingual Dutch-speaking families and children from families wherein at least one non-Dutch language was spoken. In follow-up questions, children who indicated that they spoke at least one non- Dutch language at home, were asked to report which language(s) this/these was/were and which of these non-Dutch languages was spoken the most at home (further regarded as the HL). In a next set of questions, children were asked which language (Dutch or non-Dutch) they mostly used to talk to parents and siblings and vice versa.
} 
expert panel consisting of child researchers and professionals with expertise in working with multilingual children, the implementation of insights on questionnaire construction from cognitive test interview data, the inclusion of age-specific standard scales, and the administration of a pretest to test subjects who were similar to the sample respondents. In addition, since the survey was taken in Dutch, children's proficiency in Dutch must have been good enough for them to able to report reliably. The overall mean on Dutch proficiency was high (over 4 on a scale from 1 to 5 , see Table 1$)^{2}$ and the amount of missing data was very low, suggesting that children indeed understood what was asked. The few questions that the children raised about the survey required some clarification about a limited number of words.

Because of the young age of the respondents, several ethical issues also had to be dealt with. Consent had to be obtained from schools, parents, and children themselves (Fargas-Malet et al. 2010). Principals who agreed to participate after communication by letter or telephone about the content and purpose of the study were then asked to distribute a passive consent letter to the parents. Parents who did not want their child to participate informed the teacher and/or the researcher (but this number was negligible, 6 out of 1049 in the initial sampling frame). Finally, prior to initiating the survey the lead researcher informed children about the content, procedure and purpose of the study. They were explicitly told that they were not obliged to undertake the survey and could stop at any time they wished. They were also told that this was not a school assignment and thus anonymous, that they were the experts on the matter since the questions were about themselves and consequently, there were

\footnotetext{
${ }^{2}$ Although Dutch proficiency was also based on self-reports, and is thus also subjective to possible self-bias, research shows moderate correlations between objective tests and youths' selfevaluations of proficiency in their first and second languages (Edele et al. 2015).
} 
no right or wrong answers and that their personal information was not to be shared with their teachers or parents.

\section{Measures}

\section{Dependent variable: emotional language use of children}

Children were asked to respond on following questions: "Which language do you prefer to use when you are happy?" and "Which language do you prefer to use when you are sad"? Answering categories were 1) Dutch, 2) the HL or 3) both equally. The variables were recoded into dummy variables with ' 1 ' indicating a preference for Dutch. This was done to reduce null cells in original models. Table 1 shows that $45 \%$ of the children in our sample prefer to use Dutch when they feel happy compared to $40 \%$ when they feel sad.

\section{Independent variables}

Language Practices: Children indicated which language they mostly used to communicate with their mother and father. We constructed a variable 'Language Used by Child to Talk to Parents' with four categories: (1) children use mostly Dutch to communicate with mother and father, (2) children use mostly Dutch to talk to their mother but use a nonDutch language with their father, (3) children use mostly a non-Dutch language to talk to their mother but Dutch with their father and (4) children use a non-Dutch language to talk to both parents. In addition, children reported the language their mother and father mostly used to communicate with them. Similarly, we constructed the variable 'Language Used by Parents to Talk to Child' with the parallel categories. Table 1 shows that the patterns of language used by children to speak with their parents are very similar to the parents' language use patterns with them. A majority of the children report that non-Dutch languages are mostly used as the language of communication within the parent-child subsystem. The dummy variable 'More than One Non-Dutch Language at Home' indexes the number of non- 
Dutch languages that children report speaking at home with ' 1 ' referring to two or more languages and ' 0 ' to only one non-Dutch language. A quarter of the children report at least two or more non-Dutch languages spoken at the home, indicating significant linguistic diversity within the family settings of Antwerp youth.

Table 1: Frequencies, means and standard deviations of the variables

\begin{tabular}{|c|c|c|c|}
\hline Variable & $\begin{array}{r}\text { Mean or } \\
\text { percentage }\end{array}$ & Standard Deviation & Range \\
\hline \multicolumn{4}{|l|}{ Dependent Variables } \\
\hline Dutch Only When Happy (Yes = 1) & $44.74(221)$ & & \\
\hline Dutch Only When Sad (Yes $=1)$ & $40.00(196)$ & & \\
\hline \multicolumn{4}{|l|}{ Background Characteristics } \\
\hline \multicolumn{4}{|l|}{ Ethnic Background: } \\
\hline Moroccan & $58.80(294)$ & & \\
\hline East-EU & $16.60(83)$ & & \\
\hline Turkish & $13.20(66)$ & & \\
\hline Mixed & $11.40(57)$ & & \\
\hline \multicolumn{4}{|l|}{ Generational Status: } \\
\hline 1 st & $28.20(141)$ & & \\
\hline 2nd & $49.40(247)$ & & \\
\hline 2.5 & $22.40(112)$ & & \\
\hline Age at arrival (for foreign born) & 1.54 & 3.19 & $0-12$ \\
\hline \multicolumn{4}{|l|}{ Sibship Position } \\
\hline Youngest Child & $19.80(99)$ & & \\
\hline Middle Child & $48.00(240)$ & & \\
\hline Oldest Child & $32.20(161)$ & & \\
\hline Gender $($ Girl $=1)$ & $49.00(245)$ & & \\
\hline \multicolumn{4}{|l|}{ Language Practices } \\
\hline \multicolumn{4}{|c|}{ Language Used by Child to Talk to Parents } \\
\hline Dutch for Mother \& Father & $12.65(63)$ & & \\
\hline Dutch for Mother Only & $16.87(84)$ & & \\
\hline Dutch for Father Only & $14.26(71)$ & & \\
\hline Non-Dutch for Mother \& Father & $56.22(280)$ & & \\
\hline \multicolumn{4}{|c|}{ Language Used by Parents to Talk to Child } \\
\hline Mother \& Father use Dutch & $11.47(57)$ & & \\
\hline Only Mother uses Dutch & $15.29(76)$ & & \\
\hline Only Father uses Dutch & $15.90(79)$ & & \\
\hline Mother \& Father use Non-Dutch & $56.34(285)$ & & \\
\hline Exposure to Dutch by Siblings & $77.06(383)$ & & \\
\hline$>1$ Non-Dutch Language $(Y e s=1)$ & $25.50(127)$ & & \\
\hline \multicolumn{4}{|l|}{ Language Proficiency } \\
\hline Dutch Proficiency Child & 4.58 & .61 & $1-5$ \\
\hline
\end{tabular}




\begin{tabular}{lrrr}
\hline Variable & $\begin{array}{r}\text { Mean or } \\
\text { percentage }\end{array}$ & Standard Deviation & \\
\hline HL Proficiency Child & 4.28 & .92 & Range \\
& & & \\
Language Attitudes & & & \\
Importance of Child Learning Dutch to Parents & 4.52 & .80 & $1-5$ \\
Importance of Child Learning Dutch to Child & 4.43 & .83 & $1-5$ \\
Importance of Child Learning HL to Parents & 4.36 & .83 & $1-5$ \\
Importance of Child Learning HL to Child & 4.24 & .98 & $1-5$ \\
\hline
\end{tabular}

Note: Numbers in parentheses are absolute frequencies (n).

Language Proficiency: Children were asked how well they understand, speak, write and read Dutch and the HL on a scale from 1 to 5. However, since some children might have an oral HL (e.g. Moroccan Berber languages), proficiency of children in the HL and Dutch were calculated as the mean of the understanding and speaking items. In general, children think they are quite proficient in both Dutch $(\overline{\mathrm{x}}=4.58 ; \mathrm{SD}=0.61$; Table 1$)$ and their HL $(\overline{\mathrm{x}}=$ 4.28; $\mathrm{SD}=0.92 ;$ Table 1).

Language Attitudes: Children indicated how important it is to learn Dutch and how important it is to learn the HL on a scale from ' 1 ' (unimportant) to ' 5 ' (very important). With parallel wording children were asked to rate how important it was to their mother and father that their children learn Dutch. Because differences between perceptions of mothers' versus fathers' attitudes were negligible, the variable 'Importance of Learning Dutch to Parents' was calculated as the mean of the two parental scores. The variable 'Importance of Learning HL to Parents' was constructed the same way. Table 1 indicates that children and parents share a strong advocacy for active bilingualism, with mean scores all higher than 4 .

Background Characteristics: We constructed the variable 'Ethnicity' from the reported birth countries of the children, of their parents and of their grandmothers from their mother's and father's sides. Four categories were retained: Moroccan (56\%), Eastern European (incl. Russia) (20\%), Turkish (13\%) and Mixed (i.e. children from interethnic partnerships) (12\%). This distribution reflects the Moroccans' position as largest immigrant group in Antwerp (Lodewijckx 2013; Studiedienst van de Vlaamse Regering 2016). The 
variable 'Migration Generation' consists of three categories. First generation children were born outside of Belgium (30\%). Second generation children were born in Belgium but have parents that were both born abroad (48\%). 2.5 generation children are born in Belgium and have one parent born abroad and the other parent born in Belgium (22\%). 'Age at Arrival' is the age at which foreign-born children arrived in Belgium (children born in Belgium get a ' 0 ' code). This first generation arrived in Belgium, on average, between one and two years old, well before the start of the compulsory elementary school period ( 5 years old) and even before the start of facultative pre-school kindergarten (2,5 years of age). However, the standard deviation is quite large so a significant number of children did arrive in Belgium as kindergartners. Lastly, the dummy variable 'Girl' refers to the gender of the child with girls being coded as ' 1 ' $(49 \%)$.

\section{Method}

We estimated the likelihood that the child reports a preference for Dutch when feeling happy and sad via binomial logistic regression. We used the 'proc genmod' procedure in SAS with the 'repeated measure' statement to handle potential data clustering within schools, our primary sampling unit. This approach provides robust standard error estimates that correct for possible dependence among the repeated observations (Allison 1999). We chose this method over the standard multilevel analysis models because of the relatively small number of schools and the absence of significant variance between schools in our sample.

Cases with missing values were list-wise deleted. All models were evaluated for multicollinearity and no problems were found (all VIF coefficients were under 10). Because of the correlation between the variables 'Age at Arrival' and 'Migration Generation' due the former's applicability only to the first generation, the VIF coefficients of the models containing both these variables were slightly higher (over 4). 


\section{Results}

\section{RQ 1: Are emotional language use preferences of children dependent upon the} languages used by parents and children to communicate with each other?

Model 1 in Table 2 focuses on the language practices within the household.

Children's preference for Dutch as their emotional language is strongly associated with the language practice of children with their parents. Children who mostly use Dutch to talk to both parents are much more likely to have Dutch as the preferred emotional language. Though the effect is significantly smaller, children who use Dutch to talk to their mother are also more likely to use Dutch when they are $\operatorname{sad}(\beta=.65 ; p<.01)$ but not when they are happy. The language practice of parents also has an effect on the emotional preferences of the child but the coefficients are smaller. When parents speak Dutch with the child (either both or only one parent), this increases the likelihood that Dutch is the preferred emotional language when children are happy but not when they feel sad. Only when fathers use Dutch with the children, $(\beta=.81 ; p<.05)$ do we observe a significant effect on children's preference for Dutch in a negative emotion situation. This result might arise in specific situations in which children feel sad due to conflict within the family (e.g. punishments). Previous studies have shown that the father in immigrant families is often regarded as the authority figure (Pels and De Haan 2003, 2016) and as such, fathers who predominantly use Dutch would be the one who punishes the child. Therefore, an association might be established between father's use of Dutch and children's own language preference when they feel unhappy.

Interestingly, language practices of siblings are also a good predictor of children's emotional language use preferences. If there are siblings in the household who use Dutch to talk to the respondent, chances increase that responding child will prefer Dutch when they are happy $(\beta=.71 ; p<.01)$ and even more strongly when they are sad $(\beta=1.00 ; p<.001)$. The model further shows that if there is more than one non-Dutch language spoken in the 
household, this raises the chance of Dutch being the preferred language when being happy $(\beta=.31 ; p<.05)$ but it is not related to preferring Dutch when children are feeling sad.

\section{RQ 2: Are emotional language use preferences of children determined by their proficiency level in the HL and/or IL?}

Model 2 in Table 2 contains measures of the child's proficiency in Dutch and the HL. The observed associations are in the expected directions: the more proficient in Dutch, the more likely children are to have Dutch as their preferred emotional language. However, the better the child is in understanding and speaking their HL, the less likely it is that they will prefer to use Dutch when they are feeling happy or sad. This points to the importance of being proficient in a language to have it be able to function as an emotional language.

Table 2: Gross Logistic Regression Models Predicting the Log Odds of a Child Reporting a Preference for Dutch when Feeling Happy or Sad

\begin{tabular}{lrr}
\hline & Dutch when Happy & Dutch when Sad \\
\hline Model 1: Language Practices & $-1.41(.27)$ & $-1.76(.28)$ \\
Intercept & & \\
Language Used by Child to Talk to Parents ${ }^{\mathrm{a}}$ & $1.37 * * *(.41)$ & $1.15^{* *}(.40)$ \\
$\quad$ Dutch for Mother \& Father & $.48(.32)$ & $.95 * *(.33)$ \\
$\quad$ Dutch for Mother Only & $.12(.37)$ & $-.08(.51)$ \\
$\quad$ Dutch for Father Only & & $.28(.31)$ \\
Language Used by Parents to Talk to Child ${ }^{\mathrm{b}}$ & $.87 *(.37)$ & $.09(.33)$ \\
$\quad$ Mother \& Father use Dutch & $.54+(.29)$ & $.81 *(.39)$ \\
Only Mother uses Dutch & $.66 *(.31)$ & $1.00^{* * *}(.28)$ \\
Only Father uses Dutch & $.71 * *(.29)$ & $.12(.15)$ \\
Exposure to Dutch by Siblings (Ref=No) & $.31 *(.15)$ & 607 \\
$>$ 1 Non-Dutch Language (Ref $=N o)$ & 616 & 609 \\
QIC & 620 & \\
QICu & & $-.40(.75)$ \\
& & $.65 * * *(.17)$ \\
Model 2: Language Proficiency & $.68(.89)$ & $-.71 * * *(.12)$ \\
Intercept & $.47 * *(.17)$ & 608 \\
Dutch Proficiency Child & $-.71 * * *(.12)$ & 608 \\
HL Proficiency Child & 633 & 633 \\
QIC & & \\
QICu & &
\end{tabular}

Model 3: Language Attitudes Intercept 
Importance of Child Learning Dutch to Parents

Importance of Child Learning Dutch to Child

$+\mathrm{p}<.10$ level; $* \mathrm{p}<.05 ; * * \mathrm{p}<.01 ; * * * \mathrm{p}<.001$

NOTE: Numbers in parentheses are standard errors.

a. Reference Category is Child Uses Non-Dutch to Talk to Mother \& Father. b. Reference Category is Mother \& Father Use Non-Dutch to Talk to Child.

\section{RQ 3: Do language attitudes of children and/or of parents influence emotional language use preferences of children?}

Model 3 in Table 2 describes the effects of language attitudes of parents and children on the likelihood of preferring Dutch as the emotional language. Most relationships are in the expected direction: the more parents and children value the learning of Dutch, the more likely it is that children will prefer Dutch. For HL learning, the opposite pattern is found. However, the analysis does reveal some unexpected results. First of all, the value that parents' attach to the learning of Dutch or the HL does not affect children's preference for Dutch when they are sad. Second, while the relationship is strongly positive for children's own evaluations of the importance of Dutch $(\beta=.49 ; p<.001)$, it is negative for children's perceptions of their parents' Dutch attitudes $(\beta=-.25 ; p<.05)$. One explanation might be that parents who are more strongly engaged in their children learning Dutch might be the ones who worry that their child has not sufficiently mastered Dutch. This parental pressure might lead children to develop negative associations with Dutch. However, this implies that controlling for proficiency of children should make the effect abate, which in fact it does (see results RQ5 and Table 3). Lastly, children's ideas about the value of learning their HL affects the likelihood that they prefer Dutch when they are sad, but not when they are happy. 


\section{RQ5: What are the net effects of language practice, language proficiency and}

\section{language attitudes on the emotional language preferences of children?}

Table 3 shows the coefficients for the full model containing all five sets of variables. Model 6 includes all the core independent variables. In Model 7, background characteristics were incorporated. Model 6 shows that the explanatory power of language practices of children themselves diminishes significantly. Intermediate models (available upon request) indicate that this result is primarily due to the inclusion of children's language proficiency variables. Prior research has often found that proficiency and practice tend to reinforce each other, although they are two distinct dimensions (Grosjean 2010). Language practices of parents do remain a significant predictor of children's emotional language. If both parents use Dutch, children are more likely to prefer Dutch in happy situations $(\beta=1.08 ; p<.01)$ and, though to a much smaller degree, when children feel $\operatorname{sad}(\beta=.60 ; p<.10)$. In addition, the effect of Dutch-speaking fathers on emotional preferences of children in negative emotion situations remains $(\beta=.69 ; p<.10)$. In addition, the results suggest that siblings' use of Dutch remains a good indicator of children's emotional preferences, especially in negative emotional situations. However, the effect of number of non-Dutch languages is no longer present in the full model.

The estimated effects of language proficiencies imply that children's preference for Dutch as their emotional language is determined by their proficiency in the HL and not by their proficiency in Dutch. This suggests that proficiency in the HL functions as threshold: only when children are not good enough in the HL, they will resort to Dutch regardless of their proficiency in it, perhaps because of the negative emotions associated with experiences of HL attrition. Models 6 and 7 further show that parents' language attitudes no longer affect emotional language preferences. However, children's attitudes remain important predictors although attitudes about learning the HL and Dutch work differently depending on the emotion involved. Children who find it very important to learn Dutch are more likely to 
prefer Dutch when they are happy but not when they are sad. Conversely, the more children value the learning of the HL, the smaller the probability that they will prefer Dutch when they are sad, but not when they are happy.

Table 3: Full Logistic Regression Model Predicting the Log Odds of a Child Reporting a Preference for Dutch when Feeling Happy or Sad

\begin{tabular}{|c|c|c|c|c|}
\hline & \multicolumn{2}{|c|}{ Dutch when Happy } & \multicolumn{2}{|c|}{ Dutch when Sad } \\
\hline & Model 6 & Model 7 & Model 6 & Model 7 \\
\hline Intercept & $.05(1.36)$ & $1.22(1.446)$ & $-1.03(1.13)$ & $-.56(1.19)$ \\
\hline \multirow{2}{*}{\multicolumn{5}{|c|}{$\begin{array}{l}\text { Language Used by Child to Talk to } \\
\text { Parents }^{\mathrm{a}}\end{array}$}} \\
\hline & & & & \\
\hline Both Parents Dutch & $.91 *(.39)$ & $.63(.42)$ & $.55(.45)$ & $.26(.44)$ \\
\hline Only Mother Dutch & $.14(.43)$ & $-.07(.50)$ & $.64 *(.33)$ & $.57(.42)$ \\
\hline Only Father Dutch & $-.02(.46)$ & $-.18(.51)$ & $-.34(.60)$ & $-.41(.60)$ \\
\hline \multicolumn{5}{|l|}{$\begin{array}{l}\text { Language Used by Parents to Talk to } \\
\text { Child }^{\mathrm{b}}\end{array}$} \\
\hline Both Parents Dutch & $.90 * *(.35)$ & $1.08 * *(.39)$ & $.35(.30)$ & $.60+(.34)$ \\
\hline Only Mother Dutch & $.56+(.33)$ & $.62(.40)$ & $.04(.36)$ & $.10(.46)$ \\
\hline Only Father Dutch & $.55(.34)$ & .48 (.37) & $.72+(.43)$ & $.69+(.38)$ \\
\hline $\begin{array}{l}\text { Exposure to Dutch by Siblings }(\mathrm{Ref}= \\
\mathrm{No})\end{array}$ & $.59 *(.28)$ & $.55^{*}(.27)$ & $.81 * *(.30)$ & $.90 * *(.30)$ \\
\hline$>1$ Non-Dutch Language $(\operatorname{Ref}=\mathrm{No})$ & $.34+(.20)$ & $.15(.25)$ & $.17(.15)$ & $-.08(.13)$ \\
\hline Dutch Proficiency Child & $.08(.16)$ & $.04(.18)$ & $.30(.20)$ & $.30(.21)$ \\
\hline HL Proficiency Child & $-.48 * * *(.12)$ & $-.46 * * *(.12)$ & $-.54 * * *(.13)$ & $-.56 * * *(.11)$ \\
\hline $\begin{array}{l}\text { Importance of Child Learning Dutch to } \\
\text { Parents }\end{array}$ & $-.17(.13)$ & $-.19(.16)$ & $.08(.21)$ & $.09(.22)$ \\
\hline $\begin{array}{l}\text { Importance of Child Learning Dutch to } \\
\text { Child }\end{array}$ & $.42 * * *(.12)$ & $.47 * * *(.13)$ & $.16(.16)$ & $.18(.18)$ \\
\hline $\begin{array}{l}\text { Importance of Child Learning HL to } \\
\text { Parents }\end{array}$ & $-.11(.11)$ & $-.11(.14)$ & $.08(.10)$ & $.09(.12)$ \\
\hline $\begin{array}{l}\text { Importance of Child Learning HL to } \\
\text { Child }\end{array}$ & $-.05(.14)$ & $-.12(.13)$ & $-.22 *(.10)$ & $-.30 * *(.10)$ \\
\hline \multicolumn{5}{|l|}{ Ethnic Background ${ }^{\mathrm{c}}$} \\
\hline East-EU & & $-.98 *(.43)$ & & $-.55+(.31)$ \\
\hline Turkish & & $-.77(.51)$ & & $-1.45^{* *}(.46)$ \\
\hline Mixed & & $.25(.35)$ & & $.16(.42)$ \\
\hline \multicolumn{5}{|l|}{ Generational Status ${ }^{\mathrm{d}}$} \\
\hline Second & & $-.42(.47)$ & & $.08(.52)$ \\
\hline 2.5 & & $-.63(.60)$ & & $-.19(.61)$ \\
\hline Age at Arrival ${ }^{\mathrm{e}}$ & & $-.07(.07)$ & & $.04(.06)$ \\
\hline \multicolumn{5}{|l|}{ Sibship Position ${ }^{\mathrm{f}}$} \\
\hline Youngest Child & & $.40(.34)$ & & $.58 *(.27)$ \\
\hline Middle Child & & $-.17(.24)$ & & $-.26(.22)$ \\
\hline Gender $(\operatorname{Ref}=$ Boy $)$ & & $-.04(.23)$ & & $-.03(.31)$ \\
\hline
\end{tabular}


QIC

$$
602
$$

575

594

551

$\mathrm{QICu}$

605

576

594

553

$+\mathrm{p}<.10$ level; * $\mathrm{p}<.05 ; * * \mathrm{p}<.01 ; * * * \mathrm{p}<.001$

NOTE: Numbers in parentheses are standard errors.

a. Reference Category is Child Uses Non-Dutch to Talk to Mother \& Father. b. Reference Category is Mother \& Father Use Non-Dutch to Talk to Child. c. Reference Category is Moroccan. d. Reference Category is First Generation. e. For Foreign Born Children f. Reference Category is Oldest Child

Controlling for background characteristics does not substantively alter the estimated effects of factors driving our research questions. In other words, linguistic characteristics of children and their parents exert a largely independent influence on family life, along with general demographic indicators of acculturation. Contrary to our expectations, we did not find a significant effect of age at arrival, a proxy indicator for age of Dutch acquisition for foreign-born children. Also, the results do not corroborate the assimilation hypothesis suggesting that children's emotional language preferences should follow a generational gradient. Second generation children do not differ from first generation children, nor do 2.5 generation children. We do find that ethnic groups differ significantly in their emotional language use preferences. Eastern-European and Turkish children in particular are less likely than Moroccan children to prefer Dutch as their emotional language. Lastly, while gender differences were not observed, children's birth order does matter. Children who are the youngest in the family are more likely than oldest children to prefer Dutch when they are sad.

\section{Summary and Discussion}

The family plays a central role in the language socialization of children of ethnolinguistic minority groups. While there many studies focusing on the processes of language maintenance and language shift within these families, attention to the emotional language use preferences of children is still rare. Guided by the Family Language Policy framework, we explored how language practices, language attitudes and language 
proficiencies of children and their families shape children's preference for Dutch when feeling happy and sad for ethnolinguistic minority children in Antwerp, Belgium.

Using the detailed information collected by the MiNA study and an analytical sample of 500 children, we were able to investigate the net effects of language practice, language attitudes and language proficiency while controlling for important background characteristics such as ethnicity, migration generation, age at arrival, sibship status and gender of the child. We were also able to assess whether the processes driving children's language use preferences are the same in positive emotion situations as in negative emotion situations. The results suggest that children's preference for Dutch when they are feeling sad and happy are affected by the linguistic factor in much the same way. Children's preference for Dutch when feeling happy is positively related to Dutch being used by both parents and siblings and to children's own value attached to the learning of Dutch, while their proficiency in the HL is negatively related to a preference for Dutch. Standard background factors such as migration generation, gender and age at arrival were not influential save the pattern that EasternEuropean children are less likely than Moroccan children to prefer Dutch in positive emotion situations.

The likelihood that children prefer Dutch in a negative emotion situation increase when Dutch is the main communication language of both parents or of the father (but not the mother) and when there are siblings present that use Dutch, while they are negatively associated with children's HL proficiency and with the importance attached to the learning of the HL by the child itself. In addition, youngest children, Eastern-European and Turkish children are less likely to prefer Dutch compared to eldest children in the household and Moroccan children.

Thus while children's own language practices are not related to their emotional language preferences, the language their parents speak with them does matter. This suggests 
that children's emotional language preferences are in part reflective of the language that is present during the highly affective learning contexts that characterize parent-child relationships. Also, the significant association between fathers' but not mothers' use of Dutch and children's preference for Dutch when feeling sad could hint at possible moderating effects of specific parenting practices (e.g. punishments versus responsivity) between parental language practice and children's emotional language preferences. In-depth investigation of these interrelationships offers an interesting path for future research. Our results further suggest that siblings not only affect general language shift within the household (Kibler, Palacios, and Simpson Baird 2014; Kheirkhah and Cekaite 2017) but also shape individuals' emotional language shift. From pre-school until the end of middle childhood, children often spend more time with their siblings than they do with their parents or other peers. Furthermore, siblings relationships are often emotional intense, with positive and negative feelings being omnipresent (Dunn 2014). Overall, studies have found that for children of this age, peers play an increasingly important role (Rubin, Bukowski, and Parker 2006).

With regards to the importance of children's attitudes towards the learning of Dutch and the HL, it was interesting to note that these attitudes work differently depending on the emotion experienced. This finding might relate to what De Leersnyder, Mesquita, and Kim (2011) found in their study on emotional acculturation among adults. They suggest that emotional concordance, i.e. "the fit or similarity between an immigrant's emotional pattern and the one typical of the host culture reflects that immigrant's internalization of the new culture" (452), is higher for positive than for negative situations. If children's attitudes towards the HL and the IL are in fact proxies of their acculturation process, it would help explain why we find an association between Dutch language attitudes and language preferences in positive emotion situations but not in negative ones. Here children's developmental stage might also be implicated: positive emotion knowledge seems to be 
relatively accomplished by the end of primary school while knowledge of negative emotions is much more complex with the learning process continuing throughout secondary school (Doost et al. 1999). Furthermore, these patterns grounded in a feedback system wherein children's orientation towards Belgium are shaped by positive experiences related to their acculturation process, which in turn increases the emotional association between Dutch and positive feelings, but not with negative feelings like sadness or grief. For example, children who value the learning of Dutch are rewarded for this attitude by an important majority institution: the school system. Flemish schools are known to question the merit of the HL maintenance by ethnolinguistic minority children and consequently, many schools forbid or sanction the use of the HL of the school property (Pulinx, Van Avermaet, and Agirdag 2017). Overall, the results of the study offer additional insights into the mechanisms driving the emotional language preferences of ethnolinguistic minority children's and how predictors of general language acculturation processes also affect emotional language acculturation of children with an immigration background. The more families are linguistically acculturated to the host society, and thus, the more affective relationships take place in a Dutch context, the more likely it is that children will associate Dutch with emotions. Likewise, children who find themselves strongly oriented towards life in Belgium are more likely to use Dutch when they are feeling good but not when they are sad. Following the acculturation framework, we also expected that the more generally acculturated children were in Dutch (e.g. use of Dutch to talk to parents or Dutch proficiency), the more they will resort to Dutch as their emotional language. However, we did not find any evidence for this relationship. Language acculturation might explain some aspects of children's preference for Dutch, the strong emotional bonds children have with their HL still persist, making the preference for Dutch dependent on their proficiency in the HL, instead of on how skilled they already are in Dutch. 
This suggests that the emotional language shift process should not be understood as a unilinear, but rather as a multidimensional process.

This study has several limitations. First of all, we did not observe any significant effects of age at arrival and migration generation, though in previous studies these variables have been shown to be important predictors of the emotionality of languages. This is almost certainly due to the selection of our sample. Because the children are relatively young and practically all of them came to Belgium during pre-school, chances are small that a generational gradient would have been found since the language learning trajectories within this sample are more homogeneous than we would find among older age groups.

Furthermore, the age at arrival variable is only a proxy of the age of Dutch acquisition since we do not know when second generation or 2.5 generation children started to acquire Dutch as L2. However, the restriction of the sample in our study with regards to these variables can also be interpreted as an advantage since they function as a control for cohort differences, as well as for exposure to risk.

Our language use measure only assessed which language was used the most with mother, father, and siblings. Therefore, we do not known the relative amount of Dutch use versus HL use within the household with precision. Furthermore, as we already mentioned, we have no information on the language used with friends who are also important additional socialization agents for the emotional acculturation of children. Such information could sharpen our understanding of how public and private micro-systems of children interact and shape emotional language shift since we know that language use with peers often differs from language use within the home (Caldas and Caron-Caldas 2002; Yilmaz 2008).

Furthermore, because the study was administered in Dutch in a Dutch school setting, this could have resulted in some bias towards reporting Dutch as preferred language. Ethnolinguistic minority individuals have been found to shift more easily to the IL when they 
are in the public domain, and this tendency is more pronounced among more acculturated individuals (Pauwels 2004; Hammer 2017). However, our analysis specifically included predictors of acculturation to control at least partially for this issue. Our research design also explicitly differentiated the context of the survey from its content by asking questions about the family in a school setting. Previous studies have found that questioning children about family related issues while being at home increases the risk of biased reports (Havermans, Vanassche, and Matthijs 2015).

Lastly, although it is likely that the self-reports of the children do not completely correspond to objective reality (e.g. about the parents' language attitudes or about their own language proficiencies), it is still important to investigate children's understandings of their environment and themselves. While much research has been done on children's language use and preferences and its determinants (e.g. based on reports of parents or teachers), only recently has sociological research has been carried out with children, considering them to be active actors capable of reporting about their own life (Bell 2016; Borgers, De Leeuw, and Hox 2000). In the end, how children perceive themselves and their social environment will largely determine the way they think about the world, whether these perceptions are in fact objectively correct or not. In other words, recording and analysing children's first-hand perceptions and ways of interpreting and experiencing the world is just as or even more important than collecting and interpreting second-hand information from other actors. 


\section{References}

Agirdag, Orhan. 2010. "Exploring bilingualism in a monolingual school system: insights from Turkish and native students from Belgian schools." British Journal of Sociology of Education 31 (3):307-21. doi: 10.1080/01425691003700540.

Agirdag, Orhan, Katelijne Jordens, and Mieke Van Houtte. 2014. "Speaking Turkish in Belgian primary schools: Teacher beliefs versus effective consequences." Bilig 70:728.

Alba, Richard, John Logan, Amy Lutz, and Brian Stults. 2002. "Only English by the third generation? Loss and preservation of the mother tongue among the grandchildren of contemporary immigrants." Demography 39 (3):467-84. doi: https://doi.org/10.1353/dem.2002.0023.

Alba, Richard, and Victor Nee. 2003. Remaking the American mainstream: Assimilation and contemporary immigration: Harvard University Press.

Allison, Paul D. 1999. Logistic regression using the SAS sytem: Theory and application. Cary: SAS Institute.

Altinkamis, N. Feyza, and Orhan Agirdag. 2014. "Determinants of language use and attitudes among Turkish speakers in Flanders: A focus on generational difference." Bilig 70 (3):59-80.

Aycicegi, Ayse, and Catherine Harris. 2004. "BRIEF REPORT Bilinguals' recall and recognition of emotion words." Cognition \& Emotion 18 (7):977-87. doi: 10.1080/02699930341000301.

Beck, Luna, Irina R Kumschick, Michael Eid, and Gisela Klann-Delius. 2012. "Relationship between language competence and emotional competence in middle childhood." Emotion 12 (3):503-14.

Bell, Alice. 2016. "Designing and testing questionnaires for children." Journal of Research in Nursing 12 (5):461-9. doi: 10.1177/1744987107079616.

Benet-Martinez, Veronica, and Jana Haritatos. 2005. "Bicultural identity integration (BII): components and psychosocial antecedents." J Pers 73 (4):1015-49. doi: 10.1111/j.1467-6494.2005.00337.x.

Benet-Martínez, Verónica, Janxin Leu, Fiona Lee, and Michael W. Morris. 2002. "Negotiating biculturalism." Journal of Cross-Cultural Psychology 33 (5):492-516. doi: 10.1177/0022022102033005005.

Birdsong, David, and Michelle Molis. 2001. "On the evidence for maturational constraints in second-language acquisition." Journal of Memory and Language 44 (2):235-49.

Blommaert, Jan. 2013. "Citizenship, language, and superdiversity: Towards complexity." Journal of Language, Identity \& Education 12 (3):193-6. doi: 10.1080/15348458.2013.797276.

Borgers, Natacha, Edith De Leeuw, and Joop Hox. 2000. "Children as respondents in survey research: Cognitive development and response quality." Bulletin of Sociological Methodology/Bulletin de Méthodologie Sociologique 66 (1):60-75.

Caldas, Stephen J., and Suzanne Caron-Caldas. 2002. "A sociolinguistic analysis of the language preferences of adolescent bilinguals: Shifting allegiances and developing identities." Applied Linguistics 23 (4):490-514.

Caldwell-Harris, Catherine L. 2014. "Emotionality differences between a native and foreign language: theoretical implications." Front Psychol 5:1055. doi: 10.3389/fpsyg.2014.01055.

Cervantes, Christi A. 2002. "Explanatory emotion talk in Mexican immigrant and Mexican American families." Hispanic Journal of Behavioral Sciences 24 (2):138-63. doi: 10.1177/0739986302024002003. 
Ceuleers, Evy. 2008. "Variable identities in Brussels. The relationship between language learning, motivation and identity in a multilingual context." Journal of Multilingual and Multicultural Development 29 (4):291-309. doi: 10.1080/01434630802147783.

Chen, Stephen H, Morgan Kennedy, and Qing Zhou. 2012. "Parents' expression and discussion of emotion in the multilingual family: Does language matter?" Perspect Psychol Sci 7 (4):365-83. doi: 10.1177/1745691612447307.

Clycq, Noël. 2009. Van keukentafel tot "God": Belgische, Italiaanse en Marokkaanse ouders over identiteit en opvoeding. Antwerpen: Garant.

Cole, Pamela M., Laura Marie Armstrong, and Caroline K. Pemberton. 2010. "The role of language in the development of emotion regulation." In Child development at the intersection of emotion and cognition, edited by Susan D. Calkins and Martha Ann Bell, 59-77. Washington: American Psychological Association.

Cole, Pamela M., Carole J. Bruschi, and Babu L. Tamang. 2002. "Cultural differences in children's emotional reactions to difficult situations." Child Development 73 (3):98396. doi: 10.1111/1467-8624.00451.

Costigan, Catherine L, and Daphné P Dokis. 2006. "Similarities and differences in acculturation among mothers, fathers, and children in immigrant Chinese families." Journal of Cross-Cultural Psychology 37 (6):723-41.

Crul, Maurice. 2015. "Super-diversity vs. assimilation: how complex diversity in majorityminority cities challenges the assumptions of assimilation." Journal of Ethnic and Migration Studies 42 (1):54-68. doi: 10.1080/1369183x.2015.1061425.

Curdt-Christiansen, Xiao Lan. 2009. "Invisible and visible language planning: ideological factors in the family language policy of Chinese immigrant families in Quebec." Language Policy 8 (4):351-75. doi: 10.1007/s10993-009-9146-7. 2016. "Conflicting language ideologies and contradictory language practices in Singaporean multilingual families." Journal of Multilingual and Multicultural Development 37 (7):694-709. doi: 10.1080/01434632.2015.1127926.

De Houwer, Annick. 1999. "Environmental factors in early bilingual development: the role of parental beliefs and attitudes." In Bilingualism and migration, edited by Guus Extra and Ludo Verhoeven, 75-96. Berlin, Boston: De Gruyter Mouton. - 2007. "Parental language input patterns and children's bilingual use." Applied Psycholinguistics 28:411-24.

. 2011. "Language input environments and language development in bilingual acquisition." Applied Linguistics Review 2:221-40.

De Leersnyder, Jozefien, Batja Mesquita, and Heejung Kim. 2013. "Emotional acculturation." In Changing emotions, edited by Dirk Hermans, Bernard Rimé and Batja Mesquita, 127-33. Hove, UK: Psychology Press.

De Leersnyder, Jozefien, Batja Mesquita, and Heejung S. Kim. 2011. "Where do my emotions belong? A study of immigrants' emotional acculturation." Pers Soc Psychol Bull 37 (4):451-63. doi: 10.1177/0146167211399103.

Degner, Juliane, Cveta Doycheva, and Dirk Wentura. 2011. "It matters how much you talk: On the automaticity of affective connotations of first and second language words." Bilingualism: Language and Cognition 15 (01):181-9. doi: $10.1017 / \mathrm{s} 1366728911000095$.

Dekeyser, Graziela. 2016. "Meertaligheid in Antwerpen: een kinderblik." In. Leuven, BE: KU Leuven.

Dewaele, Jean-Marc. 2004a. "The emotional force of swearwords and taboo words in the speech of multilinguals." Journal of Multilingual and Multicultural Development 25 (2-3):204-22. doi: 10.1080/01434630408666529. 
2004b. "Perceived language dominance and language preference for emotional speech. ." In First language attrition: Interdisciplinary perspectives on methodological issues edited by Monika S. Schmid, Barbara Köpke, Merel Keijzer and Lina Weilemar, 81-104. Amsterdam: John Benjamins.

2010. Emotions in multiple languages. London: Palgrave Macmillan. . 2017. "Taal en emotie. Over taal." Tijdschrift over taal, tekst en communicatie 56.

Doost, Hamid T. Neshat, Ali R. Moradi, Mohammad R. Taghavi, William Yule, and Tim Dalgleish. 1999. "The development of a corpus of emotional words produced by children and adolescents." Personality and Individual Differences 27 (3):433-51. doi: 10.1016/s0191-8869(98)00253-0.

Dunn, Judy. 2014. "Siblings and socialization." In Handbook of Socialization. Theory and Research, edited by Joan E. Grusec and Paul D. Hastings, 309-27. New York: The Guilford Press.

Eisenberg, Nancy, Adrienne Sadovsky, and Tracy L. Spinrad. 2005. "Associations of emotion-related regulation with language skills, emotion knowledge, and academic outcomes." New Directions for Child and Adolescent Development 2005 (109):10918. doi: 10.1002/cd.143.

Fargas-Malet, Montserrat, Dominic McSherry, Emma Larkin, and Clive Robinson. 2010. "Research with children: methodological issues and innovative techniques." Journal of Early Childhood Research 8 (2):175-92. doi: 10.1177/1476718x09345412.

Ferré, Pilar, Teófilo García, Isabel Fraga, Rosa Sánchez-Casas, and Margarita Molero. 2010. "Memory for emotional words in bilinguals: Do words have the same emotional intensity in the first and in the second language?" Cognition \& Emotion 24 (5):76085. doi: 10.1080/02699930902985779.

Gafaranga, Joseph. 2010. "Medium request: Talking language shift into being." Language in Society 39 (02). doi: 10.1017/s0047404510000047.

Grosjean, François. 2010. Bilingual. Life and reality. Cambridge: Harvard University Press.

Hammer, Kate. 2017. "They speak what language to whom?!" Language \& Communication 56:42-54. doi: 10.1016/j.langcom.2017.04.004.

Harris, Catherine L., Jean Berko Gleason, and Ayse Aycicegi. 2006. "When is a first language more emotional? Psychophysiological evidence from bilingual speakers." In Bilingual minds: Emotional experience, expression, and representation, edited by Aneta Pavlenko, 257-83. Clevedon: Multilingual Matters.

Havermans, Nele, Sofie Vanassche, and Koen Matthijs. 2015. "Methodological challenges of including children in family research: measurement equivalence, selection bias and social desirability." Child Indicators Research 8 (4):975-97.

Huynh, Que-Lam, Angela-MinhTu D. Nguyen, and Verónica Benet-Martínez. 2011. "Bicultural identity integration." In Handbook of Identity Theory and Research, 82742.

Izard, Carroll E. 2009. "Emotion theory and research: highlights, unanswered questions, and emerging issues." Annu Rev Psychol 60:1-25. doi:

10.1146/annurev.psych.60.110707.163539.

Javier, Rafael Art. 2007. The Bilingual mind, cognition and language. New York: Springer

Kheirkhah, Mina, and Asta Cekaite. 2017. "Siblings as language socialization agents in bilingual families." International Multilingual Research Journal:1-18. doi: 10.1080/19313152.2016.1273738.

Kibler, Amanda K., Natalia Palacios, and Ashley Simpson Baird. 2014. "The influence of older siblings on language use among second-generation Latino preschoolers." TESOL Quarterly 48 (1):164-75. doi: 10.1002/tesq.151. 
Kind \& Gezin. 2018. "Number of newborns by language spoken with mother." In.: Kind \& Gezin.

King, Kendall A., and Lyn Fogle. 2008. "Bilingual parenting as good parenting: Parents' perspectives on family language policy for additive bilingualism." International Journal of Bilingual Education and Bilingualism 9 (6):695-712. doi: 10.2167/beb362.0.

Kitayama, Shinobu, Batja Mesquita, and Mayumi Karasawa. 2006. "Cultural affordances and emotional experience: socially engaging and disengaging emotions in Japan and the United States." J Pers Soc Psychol 91 (5):890-903. doi: 10.1037/0022-3514.91.5.890.

Levrau, François, Edith Piqueray, Idesbald Goddeeris, and Christiane Timmerman. 2013. "Polish immigration in Belgium since 2004: New dynamics of migration and integration?" Ethnicities 14 (2):303-23. doi: 10.1177/1468796813504100.

Lodewijckx, Edith. 2013. "Verkleuring in de centrumsteden. Een analyse van de gegevens uit het Rijksregister." In Steden binnenstebuiten! Analyses op de Stadsmonitor 2011, edited by Luk Bral and Hilde Schelfhout, 15-40. Brussel: Studiedienst van de Vlaamse Regering.

Niiya, Y., P. C. Ellsworth, and S. Yamaguchi. 2006. "Amae in Japan and the United States: an exploration of a "culturally unique" emotion." Emotion 6 (2):279-95. doi: 10.1037/1528-3542.6.2.279.

Novin, S., R. Banerjee, and C. Rieffe. 2012. "Bicultural adolescents' anger regulation: in between two cultures?" Cogn Emot 26 (4):577-86. doi: 10.1080/02699931.2011.592084.

Oliver, Rhonda, and Nola Purdie. 1998. "The attitudes of bilingual children to their languages." Journal of Multilingual and Multicultural Development 19 (3):199-211. doi: 10.1080/01434639808666352.

Ożańska-Ponikwia, Katarzyna. 2017. "Expression and perception of emotions by PolishEnglish bilinguals I love you vs. Kocham Cię." International Journal of Bilingual Education and Bilingualism:1-12. doi: 10.1080/13670050.2016.1270893.

Parada, Maryann. 2013. "Sibling variation and family language policy: The role of birth order in the Spanish proficiency and first names of second-generation Latinos." Journal of Language, Identity \& Education 12 (5):299-320. doi: $10.1080 / 15348458.2013 .835572$.

Park, Seong Man, and Mela Sarkar. 2007. "Parents' attitudes toward heritage language maintenance for their children and their efforts to help their children maintain the heritage language: A case study of Korean-Canadian immigrants." Language, Culture and Curriculum 20 (3):223-35. doi: 10.2167/lcc337.0.

Pauwels, Anne. 2004. "Language maintenance." In The handbook of applied linguistics, edited by Alan Davies and Catherine Elder, 719-37. Oxford: Blackwell Publishing.

Pavlenko, Aneta. 2004. "'Stop doing that, ia komu skazala!': Language choice and emotions in parent - child communication." Journal of Multilingual and Multicultural Development 25 (2-3):179-203. doi: 10.1080/01434630408666528.

Pels, Trees, and Mariëtte De Haan. 2003. Continuity and change in Moroccan socialization: a review of the literature on socialization in Morocco and among Moroccan families in the Netherlands. Utrecht: Verwey-Jonker Instituut.

. 2016. "Socialization practices of Moroccan families after migration." Young 15 (1):71-89. doi: 10.1177/1103308807072690.

Perlovsky, L. 2009. "Language and emotions: emotional Sapir-Whorf hypothesis." Neural Netw 22 (5-6):518-26. doi: 10.1016/j.neunet.2009.06.034. 
Pons, Francisco, Joanne Lawson, Paul L. Harris, and Marc de Rosnay. 2003. "Individual differences in children's emotion understanding: Effects of age and language." Scandinavian Journal of Psychology 44 (4):347-53. doi: 10.1111/1467-9450.00354.

Portes, Alejandro, and Rubén G. Rumbaut. 2001. Legacies. The story of the immigrant second generation. Berkeley, CA: University of California Press.

Pulinx, Reinhilde, Piet Van Avermaet, and Orhan Agirdag. 2017. "Silencing linguistic diversity: the extent, the determinants and consequences of the monolingual beliefs of Flemish teachers." International Journal of Bilingual Education and Bilingualism 20 (5):542-56. doi: 10.1080/13670050.2015.1102860.

Purdie, Nola, Rhonda Oliver, Glenys Collard, and Judith Rochecouste. 2016. "Attitudes of primary school Australian Aboriginal children to their linguistic codes." Journal of Language and Social Psychology 21 (4):410-21. doi: 10.1177/026192702237957.

Rubin, Kenneth H. , William Bukowski, and Jeffery Parker. 2006. "Peer interactions, relationships and groups." In The handbook of child psychology edited by Nancy Eisenberg, 571-645. New York: Wiley.

Safdar, Saba, Wolfgang Friedlmeier, David Matsumoto, Seung Hee Yoo, Catherine T. Kwantes, Hisako Kakai, and Eri Shigemasu. 2009. "Variations of emotional display rules within and across cultures: A comparison between Canada, USA, and Japan." Canadian Journal of Behavioural Science/Revue canadienne des sciences du comportement 41 (1):1-10. doi: 10.1037/a0014387.

Schwartz, Mila. 2008. "Exploring the relationship between family language policy and heritage language knowledge among second generation Russian-Jewish Immigrants in Israel." Journal of Multilingual and Multicultural Development 29 (5):400-18. doi: 10.1080/01434630802147916.

Schwartz, Mila, Victor Moin, and Mark Leikin. 2011. "Parents' discourses about language strategies for their children's preschool bilingual development." Diaspora, Indigenous, and Minority Education 5 (3):149-66. doi: 10.1080/15595692.2011.583505.

Spolsky, Bernard. 2004. Language policy. Cambridge, UK: Cambridge University Press.

—. 2009. Language management. Cambridge, UK: Cambridge University Press. . 2012. "Family language policy - the critical domain." Journal of Multilingual and Multicultural Development 33 (1):3-11. doi: 10.1080/01434632.2011.638072.

Stevens, Gillian, and Hiromi Ishizawa. 2007. "Variation among siblings in the use of a nonEnglish language." Journal of Family Issues 28 (8):1008-25.

Studiedienst van de Vlaamse Regering, . 2016. "Lokale Inburgerings- en Integratiemonitor." In. Brussel: Studiedienst van de Vlaamse Regering.

Timmermans, C., E. Vanderwaeren, and M. Crul. 2003. "The second generation in Belgium." International Migration Review 37:1065-90. doi: https://doi.org/10.1111/j.1747-7379.2003.tb00170.x.

Wierzbicka, Anna. 1999. Emotions across languages and cultures: Diversity and universals. Cambridge: Cambridge University Press.

Wierzbicka, Anna. 2004. "Preface: Bilingual Lives, Bilingual Experience." Journal of Multilingual and Multicultural Development 25 (2-3):94-104. doi: 10.1080/01434630408666523.

Wilson, Stephanie L., Vaishali V. Raval, Jennifer Salvina, Pratiksha H. Raval, and Ila N. Panchal. 2012. "Emotional expression and control in school-age children in India and the United States." Merrill-Palmer Quarterly 58 (1):50-76. doi: 10.1353/mpq.2012.0005.

Yilmaz, Gulsen. 2008. "Multilingualism and attrition: Turkish immigrants in the Netherlands." In. Groningen: University of Groningen. 
